\title{
Threat prediction in complex distributed systems using artificial neural network technology
}

\author{
E.V. Palchevsky ${ }^{1}$, O.I. Khristodulo ${ }^{1}$, S.V. Pavlov ${ }^{1}$ \\ teelxp@,inbox.ru $\mid$ o-hristodulo@,mail.ru | psvgis@,mail.ru \\ ${ }^{1}$ Ufa State Aviation Technical University, Ufa, Russia
}

\begin{abstract}
In the context of this article, a method for detecting threats based on their forecasting and development in complex distributed systems is proposed. Initially, the relevance of the research topic is substantiated from the point of view of the prospective use of various methods in the framework of threat management and their forecasting in complex distributed systems. Based on the analysis of these methods, a proprietary forecasting method based on the second generation recurrent neural network (RNN) was proposed. The mathematical formulation of the problem is presented, as well as the structure of this neural network and its mathematical model of selflearning, which allows achieving more accurate (with less error) results in the framework of threat prediction (in this case, the level of water rise at gauging stations) in complex distributed systems. An analysis was also made of the effectiveness of the existing and proposed forecasting methods, which showed the stability of the neural network in relation to other forecasting methods: the error of the neural network is 3-20\% of actual (real) water levels; the least squares method reaches up to 34.5\%, the numerical method in a generalized form - up to $36 \%$; linear regression model - up to $47.5 \%$. Thus, the neural network allows a fairly stable forecast of the flood situation over several days, which allows special services to carry out flood control measures.
\end{abstract}

Keywords: water level forecasting, flood situation, neural networks, neural network for forecasting.

\section{Introduction}

Currently, complex distributed systems include various components in the form of physical, biological and digital systems [1]. In the framework of this article, complex distributed systems are understood to mean technical objects, for example, potentially dangerous objects, oil pipelines, since technical objects located in a certain area, as defined in the literature (Reimers N.F. Nature Management, 1990; Mikhailov N.I. Physicalgeographical zoning, 1985, etc.) - belong to the class of complex unique geotechnical objects and have all the features of complex systems. For such systems, as a rule, there is a danger in the form of external threats that contribute to causing substantial material damage. For example, in the Republic of Bashkortostan, such a threat is spring flood, which threatens complex distributed systems due to possible flooding and flooding. To counter such threats, it is proposed to proactively predict the level of water rise in order to plan further activities by specialized services to prevent the negative impact of the flood on complex distributed systems falling into its distribution zone.

Many scientists (both domestic and foreign) are involved in this problem in a wide variety of scientific fields. To solve this problem, many approaches and methods are used, such as numerical methods, regression models, etc. [2, 4-23]. But due to the lack of works containing a description of the method of early detection of threats based on their early forecasting, it becomes relevant to use neural network approaches and technologies to solve this problem.

Thus, it seems important and necessary, using a recurrent neural network, to develop a method for early detection of threats on the basis of predicting the level of water rise in the flood period to counter them in complex distributed systems. This will give the necessary specialized services some time to carry out flood control measures.

\section{Existing solutions}

Currently, the literature describes many methods for predicting flood situations (including water levels), the most used of which, with the exception of hydrological ones, are as follows:

- least squares method;

- numerical methods;

- general regression models.

The main objective of these approaches is to use mathematical methods and models capable of producing fairly accurate short-term forecasting of water levels.

\section{Least square method}

It is a way to solve various mathematical problems and is based on minimizing the sum of the squared deviations between the original and calculated values. The main working formula for forecasting:

$$
Y_{t+1}=(x+b) \cdot a,
$$

where $Y_{t+1}$ is the predicted indicator, $t+1$ is the period for which the forecast is made, $a$ and $b$ are the coefficients of forecast indicators and period, $x$ is the symbol of time. Calculation of coefficient $a$ :

$$
a=\frac{\left(\sum_{i=1}^{n}\left(\left(Y_{t} \cdot x\right) \cdot n_{1}\right)\right)-\left(\sum_{i=1}^{n} x \cdot \sum_{i=1}^{n} Y_{t}\right)}{\sum_{i=1}^{n} x^{2}-\left(\sum_{i=1}^{n} x\right)^{2}},
$$

where $Y_{t}$ is the actual value of the time series, $n_{1}$ is the number of levels in the time series. The coefficient $b$ is calculated by the following formula:

$$
b=\frac{\sum_{i=1}^{n} Y_{t}}{n_{1}}-\frac{a \cdot \sum_{i=1}^{n} x}{n_{1}} .
$$

And for smoothing the time series by the least squares method, in order to obtain and reflect the patterns of the forecast, it is necessary to correctly determine the type of curve and the time analytical dependence:

$$
M=\sqrt{\frac{\sum_{i=1}^{n} \sum\left(Y_{t}-Y_{p}\right)^{2}}{\left(n_{1}-p-1\right) \cdot a}},
$$

where $Y_{p}$ are the calculated values of the time series, $p$ is the number of parameters of the described trend. 


\section{Numerical methods}

They represent a way to solve a mathematical problem in numerical form. In the case of forecasting, information on previously obtained data is used. Accordingly, for this, the formulas (in generalized form) of the forecast (5) and correction (6) are used:

$$
y_{i+1}=y_{i-3}+\left(h_{1} \cdot\left(2 y_{i}^{\prime} \cdot y_{i-1}^{\prime}+2 y_{i-2}^{\prime}\right)+O\left(h_{1}{ }^{5}\right)\right) \text {, }
$$

where $O\left(h_{1}^{5}\right)$ the calculated error in the forecast, $h_{1}$ is the iteration step, $i+1$ is the forecast period.

$$
y_{i+1}=y_{i-1}+\left(h_{1} \cdot\left(y_{i+1}^{\prime}+4 y_{i}^{\prime}+y_{i-1}^{\prime}\right)+O\left(h_{1}^{5}\right)\right) \text {. }
$$

\section{General regression models}

These models are used in many problems of data analysis and forecasting. One of the most common regression models is multivariate. A general view of this model is presented in the following formula:

$$
Y_{p}=f^{2} \cdot \sum_{x_{n}} x\left(x_{1}, x_{2}, x_{3} \ldots x_{n}\right)=f(x),
$$

where $Y_{p}$ is the predicted indicator, $x_{1}, x_{2}, x_{3} \ldots x_{n}$ are the factors affecting the forecast of water levels. In this case, the initial information is provided in the form of time series, and the following functions can be used to calculate the forecast: linear (8), power (9), exponential (10), exponential (11), hyperbolic (12). In formulas 8-12: $a$ and $b$ are the coefficients of forecast indicators.

$$
\begin{gathered}
Y_{p}=a+b x+b_{1} x_{1}+b_{2} x_{2}+b_{3} x_{3}+b_{4} x_{4}+\ldots+b_{n} x_{n} \\
Y_{p}=a x_{1} b_{1}+x_{2} b_{2}+x_{3} b_{3}+x_{4} b_{4}+\ldots+x_{n} b_{n} \\
Y_{p}=a_{0} \cdot\left(b_{1} x_{1}\right)+a_{1} \cdot\left(b_{2} x_{2}\right)+a_{2} \cdot\left(b_{3} x_{3}\right)+\cdots \\
+a_{n} \cdot\left(b_{n} x_{n}\right) \\
Y_{p}=a_{0}+b|x|+b_{1} x_{1}+b_{2} x_{2}+\ldots+b_{n} x_{n} \\
Y_{p}=\frac{1}{q+b_{1} x_{1}+b_{2} x_{2}+b_{3} x_{3}+\ldots+b_{n} x_{n}} .
\end{gathered}
$$

In practice, the linear (8) function of the multivariate regression model is often used because of the simplicity of constructing the multiple regression equation.

The results of predicting water levels at gauging stations and a comparison of these methods with the proposed solution of the authors are presented in section 4 .

\section{Development of a method for predicting water levels based on a second generation recurrent neural network}

One of the main parameters of the possible impact of the flood situation in a certain territory (for example, the Republic of Bashkortostan) is $H$ - the level of water rise in water bodies, measured daily at n-posts by employees of the regional department of hydrometeorology and environmental monitoring. We introduce the following notation: $H_{j i}^{k}$ is the water level value measured at the $k$-th post on the $i$-th the date of the $j$-th year. Here $i=\overrightarrow{1, n}$, where $n$ is the number of measuring posts involved in the calculations, $j$ is the number of the year, $i$ is the specific measurement date.

The task of forecasting is to calculate the water level value for the next $i+1$ day on a specific current $i$-th day of measurement, i.e. $H_{j i+1}^{k}$, or after 2 days on $i+2$ day, i.e. $H_{j i+2}^{k}$ or after $l$ days - on the $i+l$-th day, i.e. $H_{j i+l}^{k}$ for any $k$.

To solve this problem, it is proposed to use the results of previous measurements of the water level $H_{j i}^{k}$ at all control posts located in the considered territory (in our case, the Republic of Bashkortostan) for all previous years. The proposed forecasting method is based on the construction of a recurrent neural network, the structure and algorithm of work (with training stages) of which are presented in fig. 1 and fig. 2: Initially, data (gauging stations codes, dates, water levels) enter the input layer of the neural network for further processing in the intermediate link (layers) of the RNN for the purpose of training. Teaching without a teacher is based on the integration of the methods of back propagation of error and Rosenblatt for a more accurate forecast of water level at hydrological posts. At the output of the neural network, we obtain the predicted values of the water levels for a given period of days.

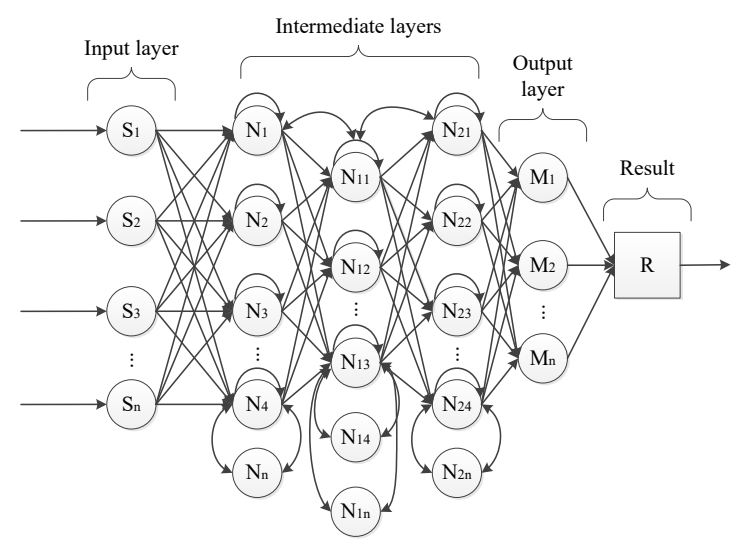

Fig. 1. Structure of the developed RNN

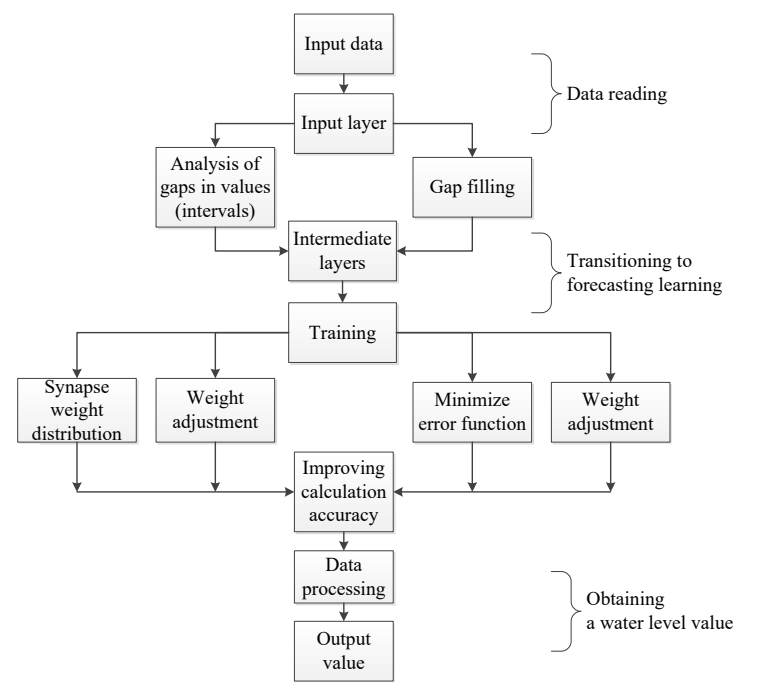

Fig. 2. Neural network algorithm with training stages for predicting water levels

From a mathematical point of view, this network is characterized by the combination of signals in the input layer (node, vector) $C\left(i_{1}\right)$, and the relationship between the intermediate and output layers is expressed as follows:

$C\left(i_{1}+1\right)=f\left((x(i)) \cdot x\left(\left(i_{1}-1\right)\right) \cdot C\left(i_{1}-(N-1)\right) \cdot\right.$

- $\left.C_{1}\left(i_{1}-1\right) \cdot C_{1}\left(i_{1}-P\right)\right)$

where $N-1$ is the delay of the input signal (quantity), $P$ is the delay of the output signal (quantity), $i_{1}$ is the number of neurons in the intermediate layers. Thus, in this case, a recurrent neural network can be characterized by the set of numbers $\left\{N, P, I_{1}\right\}$. Therefore, the vector $C\left(i_{1}\right)$ supplied to the input of the network has the following form: 
$C\left(i_{1}\right)=\left[1 \cdot\left(C \cdot\left(i_{1}\right)\right) \cdot\left(C \cdot\left(i_{1}-1\right)\right) \cdot \ldots \cdot\left(C \cdot\left(i_{1}-(N-1)\right)\right)\right.$,

$\left.\left(\left(C_{1} \cdot\left(i_{1}-P\right)\right) \cdot\left(C_{1} \cdot\left(i_{1}-P+1\right)\right) \cdot \ldots \cdot\left(C_{1} \cdot\left(i_{1}-1\right)\right)\right)\right]^{T}$.

The neuron itself has a sigmoidal activation function with a range of values $(0,1)$, described by the equation:

$$
\psi=\frac{1}{1+e^{-Q}} \text {. }
$$

We denote $U_{i}$ as the sum of the signals of each $i$-th neuron of all $j$-th intermediate layers, and $g$ is the sum of the signals of each $i$-th neuron in the output layer, then

$$
U_{i}=\sum_{j=0}^{N+P} w_{i j} \cdot C_{j},
$$

where $w_{i j}=f\left(U_{i}\right)$. Respectively,

$$
g=\sum_{i=0}^{i_{1}} w_{i} \cdot C\left(i_{1}\right)
$$

where $\mathrm{C}\left(i_{1}\right)=f(g)$. Thus, the output is the result in the form of an output data signal $\left(I_{1}\right)$. A mathematical model of training a neural network for predicting water levels is presented in subsection 3.1.

\section{Neural network training for predicting water levels}

The main idea of the training method with the back propagation of the error is to spread the error signals from the outputs of the RNN to its inputs. Partially, this method of training a recurrent neural network was used in predicting and countering cyber threats [3]. The initial task is to minimize the error function:

$$
E=\frac{1}{2} \sum_{j=1}^{p}\left(y_{j}-d_{j}\right)^{2}
$$

where $y_{j}$ is the obtained value of the $j$-th output of the $\mathrm{RNN}$, a $d_{j}$ is the reference value of the $j$-th output of the neural network. Accordingly, the minimization of $E$ is determined by the gradient descent method. At the first stage, there is an automatic adjustment of the weight coefficients of the synapses:

$$
\Delta w_{i j}=-m \cdot \frac{d E}{d w_{i j}},
$$

where $w_{i j}$ is the synapse weight, $-m(0<m<1)$ is the neural network learning rate, expressed by a coefficient. Next, it is necessary to disclose (8) for more accurate training of the neural network. In this way,

$$
\frac{d E}{d w_{i j}}=\frac{d E}{d y_{j}} \cdot \frac{d y_{j}}{d s_{j}} \cdot \frac{d s_{j}}{d w_{i j}},
$$

where $s_{j}$ is the sum of the input signals of each neuron $\mathrm{RNN}$, and $y_{j}$ is the output of the $j$-th neuron. Respectively,

$$
\frac{d E}{d y_{j}}=\sum_{k} \frac{d E}{d y_{k}} \cdot \frac{d y_{k}}{d s_{k}} \cdot \frac{d s_{k}}{d y_{j}}=\sum_{k} \frac{d E}{d y_{k}} \cdot \frac{d y_{k}}{d s_{k}} \cdot w_{j k}^{[n+1]},
$$

where $k$ is the number of neurons in the $n+1$ layer. Also for disclosure (19) we introduce a new variable:

$$
\delta_{j}^{[n+1]}=\frac{d E}{d y_{j}} \cdot \frac{d y_{j}}{d s_{j}} .
$$

After entering the variable, we obtain recursive formulas for the output (23) and input (24) layers of the RNN:

$$
\begin{gathered}
\delta_{i}^{[n]}=\frac{d y_{i}}{d s_{i}} \cdot\left(\mathrm{y}_{i}^{[n]}-d_{i}\right), \\
\delta_{j}^{[n]}=\frac{d y_{j}}{d s_{j}} \cdot \sum_{k} \delta_{k}^{[n+1]} \cdot w_{j k}^{[n+1]} .
\end{gathered}
$$

Thus, the disclosed formula (25) for automatically adjusting the weight coefficients of the synapses is as follows:

$$
\Delta w_{i j}=-m \cdot \delta_{j}^{[n]} \cdot y_{i}^{[n-1]} .
$$

In the case of the Rosenblatt method, everything is different, since it was originally intended for the training of a single-layer perceptron. Thus, the rule for training a recurrent neural network is as follows:

$$
q_{i j}(t+1)=q_{i j}(t)+a_{1} \cdot x_{i} \cdot d_{j}
$$

Next, it is necessary to integrate the training rules (26), the error minimization functions (18) and the weight adjustment of the synapse coefficients (25) in order to increase the accuracy of training and, as a result, the predicted values:

$$
H_{j i+1}^{k}=\frac{\left(q_{i j(t+1)} \cdot\left(\frac{1}{2} \sum_{j=1}^{p}\left(y_{j}-d_{j}\right)^{2}\right)\right) \cdot H_{j i}^{k}}{\Delta w_{i j}}
$$

Thus, based on the Rosenblatt methods and the back propagation of the error, formula (27) was obtained, which allows one to increase the accuracy of forecasting water levels at hydrological posts (the results are presented in Section 4).

\section{Analysis of the effectiveness of the proposed method for predicting water levels}

To analyze the effectiveness of the proposed method for predicting water levels, we used long-term data on measuring water levels at gauging stations provided by the Bashkir Administration for Hydrometeorology and Environmental Monitoring (Bashhydromet) from 01.01.2000 to 15.05.2019 years in the form of: code of a hydrological post, date and water level at the gauging station.

During the experiment, many iterations were carried out to calculate the predicted levels of water rise for the entire period of long-term observations - from 01.01.2001 to 31.12.2019. The total array of data used in the experiment is 13800 (hydrological station code, date and water level), of which $66 \%$, these are data from long-term observations from 01.01 .2000 to 31.12 .2013 , fed to the input neural networks, and the remaining 34\% (01.01.2014 $-31.03 .2019)$ - for training. From $34 \%$ of the data, the last 10 days are taken to predict water levels for the next 5 days, and the rest of the information is used to analyze and improve the accuracy of the forecast as part of the training.

As an example, the article presents the results of an experiment predicting the levels of water rise at three hydrological posts in Ufa, Shaksha district of Ufa and the village of Okhlebinino, Iglinsky district of the Republic of Bashkortostan during the spring flood of 2019. The experiment was carried out in two stages. The first stage was a comparison of real and predicted levels of water rise at hydrological posts at different periods of the flood when there is a rise in water levels, a peak period and a decline. The results are shown in tables 1-3, where the actual water level is actually the measured value at the hydrological station, and the predicted water level is the water level value obtained using the neural network.

The predicted values of water levels by the neural network at gauging stations at the beginning of the flood period (increase (rise) in water level) are presented in table 1 .

Table 1. Predicted values for five days of water levels at gauging stations at the beginning of the flood period (increase)

\begin{tabular}{|l|c|c|c|}
\hline The date & $\begin{array}{c}\text { Hydropost } \\
\text { number }\end{array}$ & $\begin{array}{c}\text { Real water } \\
\text { level, cm. }\end{array}$ & $\begin{array}{c}\text { Predicted water } \\
\text { level, cm. }\end{array}$ \\
\hline 01.04 .19 & \multirow{2}{*}{76289} & -11.00 & 0.00 \\
\hline 02.04 .19 & & 8.00 & 20.00 \\
\hline
\end{tabular}




\begin{tabular}{|c|c|c|c|}
\hline The date & $\begin{array}{l}\text { Hydropost } \\
\text { number }\end{array}$ & $\begin{array}{l}\text { Real water } \\
\text { level, cm. }\end{array}$ & $\begin{array}{c}\text { Predicted water } \\
\text { level, } \mathbf{c m} .\end{array}$ \\
\hline 03.04 .19 & \multirow{3}{*}{$\begin{array}{c}\text { (Ufa, Belaya } \\
\text { River) }\end{array}$} & 39.00 & 34.00 \\
\hline 04.04 .19 & & 63.00 & 50.00 \\
\hline 05.04 .19 & & 74.00 & 86.00 \\
\hline 01.04 .19 & \multirow{5}{*}{$\begin{array}{c}3000014 \\
\text { (microdistrict } \\
\text { Shaksha, Ufa) }\end{array}$} & 124.00 & 150.00 \\
\hline 02.04 .19 & & 131.00 & 147.00 \\
\hline 03.04 .19 & & 134.00 & 160.00 \\
\hline 04.04 .19 & & 134.00 & 161.00 \\
\hline 05.04 .19 & & 160.00 & 180.00 \\
\hline 01.04 .19 & \multirow{5}{*}{$\begin{array}{c}76288 \\
\text { (Iglinsky } \\
\text { district, the } \\
\text { village of } \\
\text { Okhlebinino) }\end{array}$} & 291.00 & 300.00 \\
\hline 02.04 .19 & & 270.00 & 290.00 \\
\hline 03.04 .19 & & 281.00 & 305.00 \\
\hline 04.04 .19 & & 296.00 & 312.00 \\
\hline 05.04 .19 & & 323.00 & 330.00 \\
\hline
\end{tabular}

The predicted values of the water levels by the neural network at gauging stations during the flood peak are presented in table 2 .

Table 2. Predicted values for five days of water levels at

\begin{tabular}{|c|c|c|c|}
\hline $\begin{array}{l}\text { The } \\
\text { date }\end{array}$ & $\begin{array}{l}\text { Hydropost } \\
\text { number }\end{array}$ & $\begin{array}{l}\text { Real water } \\
\text { level, cm. }\end{array}$ & $\begin{array}{l}\text { Predicted water } \\
\text { level, } \mathrm{cm} .\end{array}$ \\
\hline 15.04 .19 & \multirow{5}{*}{$\begin{array}{c}76289 \\
\text { (Ufa, Belaya } \\
\text { River) }\end{array}$} & 350.00 & 395.00 \\
\hline 16.04 .19 & & 368.00 & 424.00 \\
\hline 17.04 .19 & & 366.00 & 430.00 \\
\hline 18.04 .19 & & 346.00 & 400.00 \\
\hline 19.04 .19 & & 315.00 & 390.00 \\
\hline 15.04 .19 & \multirow{5}{*}{$\begin{array}{c}3000014 \\
\text { (microdistrict } \\
\text { Shaksha, Ufa) }\end{array}$} & 323.00 & 380.00 \\
\hline 16.04 .19 & & 338.00 & 390.00 \\
\hline 17.04 .19 & & 323.00 & 370.00 \\
\hline 18.04.19 & & 327.00 & 360.00 \\
\hline \begin{tabular}{|l|}
19.04 .19 \\
\end{tabular} & & 338.00 & 360.00 \\
\hline 15.04 .19 & \multirow{5}{*}{\begin{tabular}{|c|}
76288 (Iglinsky \\
district, the \\
village of \\
Okhlebinino) \\
\end{tabular}} & 621.00 & 670.00 \\
\hline \begin{tabular}{|l|}
16.04 .19 \\
\end{tabular} & & 622.00 & 673.00 \\
\hline \begin{tabular}{|l|}
17.04 .19 \\
\end{tabular} & & 597.00 & 630.00 \\
\hline 18.04 .19 & & 528.00 & 570.00 \\
\hline 19.04 .19 & & 515.00 & 550.00 \\
\hline
\end{tabular}

The predicted values of the water levels by the neural network at gauging stations during the flood period are presented in table 3 .
Table 3. Predicted values for five days of water levels at gauging stations during the flood period

\begin{tabular}{|c|c|c|c|}
\hline The date & $\begin{array}{c}\text { Hydropost } \\
\text { number }\end{array}$ & $\begin{array}{l}\text { Real water } \\
\text { level, cm. }\end{array}$ & $\begin{array}{c}\text { Predicted water } \\
\text { level, } \mathrm{cm} .\end{array}$ \\
\hline 29.04 .19 & \multirow{5}{*}{$\begin{array}{c}76289 \\
\text { (Ufa, Belaya } \\
\text { River) }\end{array}$} & 151.00 & 190.00 \\
\hline 30.04 .19 & & 140.00 & 180.00 \\
\hline 01.05 .19 & & 166.00 & 199.00 \\
\hline 02.05 .19 & & 188.00 & 205.00 \\
\hline 03.05 .19 & & 182.00 & 200.00 \\
\hline 29.04 .19 & \multirow{5}{*}{$\begin{array}{c}3000014 \\
\text { (microdistrict } \\
\text { Shaksha, Ufa) }\end{array}$} & 200.00 & 220.00 \\
\hline 30.04 .19 & & 204.00 & 200.00 \\
\hline 01.05 .19 & & 275.00 & 260.00 \\
\hline 02.05 .19 & & 313.00 & 300.00 \\
\hline 03.05 .19 & & 303.00 & 295.00 \\
\hline 29.04 .19 & \multirow{5}{*}{$\begin{array}{l}76288 \text { (Iglinsky } \\
\text { district, the } \\
\text { village of } \\
\text { Okhlebinino) }\end{array}$} & 365.00 & 390.00 \\
\hline 30.04 .19 & & 387.00 & 400.00 \\
\hline 01.05 .19 & & 405.00 & 420.00 \\
\hline 02.05 .19 & & 364.00 & 380.00 \\
\hline 03.05 .19 & & 329.00 & 350.00 \\
\hline
\end{tabular}

Thus, the error between the predicted and actual values of the water levels, according to the results of the experiment, is $3-20 \%$ (tables $1-3$ ).

The second stage of the experiment consisted in a comparative analysis of the data of the levels of water rise obtained using the described forecasting method based on the recurrent neural network and the known, most described in the literature sources, forecasting methods (least squares method, numerical methods and regression models).

As an example, the article presents the results of comparing the actual levels of water rise at the Ufa gauging station during the flood peak according to Bashhydromet and the forecast levels of water rise obtained on the basis of calculations by known methods (table 4).

An important difference of the proposed method for predicting water levels using a recurrent neural network in comparison with other known methods is the speed of obtaining the forecast and its correctness (more accurate) when forecasting ahead of time (for 5 days). The remaining methods considered in the experiment are more accurate only with short-term forecasting (1-2 days), the analysis results are shown in fig. 3 .

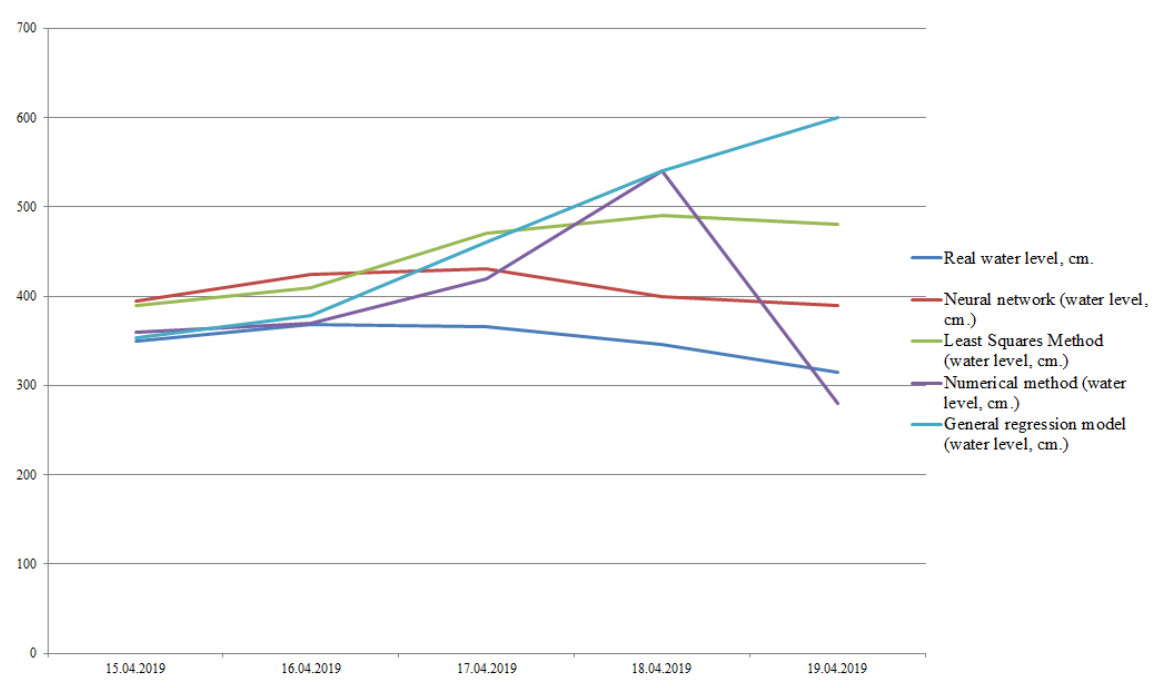

Fig. 3. An example of the results of forecasting water levels at hydrological posts 
According to the data in Table 4 and Fig. 3, it can be seen that in the first two days the forecast of water rise levels by known methods is quite accurate: the difference between the predicted values from the real ones varies from 1 to $3 \%$. However, in the following days, the gap between the predicted and real values increases: for example, when calculating by the least squares method, the error reaches $34.5 \%$, by numerical method $-36 \%$, and for a linear regression model this indicator is $47.5 \%$. It is worth noting that the implemented recurrent neural network does not give an accurate result in the first two days (in contrast to the known forecasting methods considered), but in the following days shows a more stable result.

Table 4. Comparison results of real and forecast levels of water rise at the gauging station in Ufa during the flood peak, obtained on the basis of calculations by known methods

\begin{tabular}{|c|c|c|c|c|c|}
\hline The date & $\begin{array}{l}\text { Hydropost } \\
\text { number }\end{array}$ & $\begin{array}{l}\text { Real water } \\
\text { level, cm. }\end{array}$ & $\begin{array}{l}\text { Predicted values (least } \\
\text { squares method), cm. }\end{array}$ & $\begin{array}{l}\text { Predicted values (numerical } \\
\text { method), } \mathbf{c m} .\end{array}$ & $\begin{array}{l}\text { Predicted values (general } \\
\text { regression model), cm. }\end{array}$ \\
\hline 15.04 .19 & \multirow{5}{*}{$\begin{array}{c}76289 \\
\text { (Ufa, Belaya } \\
\text { River) }\end{array}$} & 350.00 & 390.00 & 360.00 & 353.00 \\
\hline 16.04 .19 & & 368.00 & 410.00 & 370.00 & 378.00 \\
\hline 17.04 .19 & & 366.00 & 470.00 & 420.00 & 460.00 \\
\hline 18.04 .19 & & 346.00 & 490.00 & 540.00 & 540.00 \\
\hline 19.04 .19 & & 315.00 & 480.00 & 280.00 & 600.00 \\
\hline
\end{tabular}

\section{Conclusions}

A method is proposed for early detection of threats (for example, the Republic of Bashkortostan) for parrying them in complex distributed systems. The proposed forecasting method is based on the construction of a recurrent neural network, the structure and operation algorithm of which is described in the article. The results of the analysis of the effectiveness of the proposed method for predicting water levels showed an error of predicted values from 3 to $20 \%$. A comparative analysis of the data of the levels of water rise obtained using the described forecasting method based on the recurrent neural network and the well-known, most described in the literature sources, forecasting methods (least squares method, numerical methods and regression models), which revealed errors in other forecasting methods up to $47.5 \%$. Thus, the use of artificial neural network technology has shown more stable results in forecasting threats, using the example of spring flood, which will allow the special services to give the necessary time for flood control measures to prepare for the protection of complex distributed (including technical objects) systems.

\section{Acknowledgments}

The reported study was funded by RFBR, project number 20-08-00301.

\section{References}

[1] O.E.J. Wing, C.C. Sampson, P.D. Bates, "A flood inundation forecast of Hurricane Harvey using a continental-scale 2D hydrodynamic model", Journal of Hydrology X,vol. 4, 2019, P. 1-17.

[2] S.V. Pavlov, V.G. Krymsky, O.I. Khristodulo, Information support for assessing and managing water resources based on geoinformation technologies, Moscow: Dada+, 2010, p. 284.

[3] E.V. Palchevsky, O.I. Khristodulo, "Development of a self-learning method for a pulsed neural network to protect against DDoS attacks", Software \& Systems, vol. 32, no. 3, 2019, pp. 419-432.
[4] Y.V. Grebnev, A.V. Spring, "Flood monitoring and forecasting in the Krasnoyarsk Territory using neural network algorithms", Siberian Fire and Rescue Bulletin, No. 3 (10), 2018, pp. 13-16.

[5] J. Noymanee, T. Theeramunkong, "Flood Forecasting with Machine Learning Technique on Hydrological Modeling", Procedia Computer Science, vol. 156, 2019, pp. 377-386.

[6] Y. Zhou, S. Guo, F. Chang, "Explore an evolutionary recurrent ANFIS for modelling multistep-ahead flood forecasts", Journal of Hydrology. 2019. Vol. 570. pp. 343-355.

[7] S. Han, P. Coulibaly, "Bayesian flood forecasting methods: A review", vol. 551, 2017, pp. 340-351.

[8] A.E. Tekeli, H. Fouli, "Evaluation of TRMM satellite-based precipitation indexes for flood forecasting over Riyadh City", Saudi Arabia, vol. 541, Part A, 2016, pp. 471-479.

[9] K. Kim, P. Pant, E. Yamashita, "Integrating travel demand modeling and flood hazard risk analysis for evacuation and sheltering", International Journal of Disaster Risk Reduction, vol. 31, 2018, pp. 11771186.

[10] C.H. Chang, H. Lee, F. Hossain, S. Basnayke, S. Jayasinghe, F. Chishtie, D. Saah, Yu. Hanwen, K. Sothea, D.D. Bui, "A model-aided satellitealtimetry-based flood forecasting system for the Mekong River", Environmental Modelling \& Software, 2019, vol. 112, pp. 112-127.

[11] H. Shafizadeh-Moghadam, R. Valave, H. Shahabi, K. Chapi, "Shirzadi A. Novel forecasting approaches using combination of machine learning and statistical models for flood susceptibility mapping", Journal of Environmental Management, 2018, vol . 217, pp. 1-11.

[12] H. Bonakadri, A.H. Zaji, A.D. Binns, B. Gharabaghi, "Integrated Markov chains and uncertainty analysis techniques to more accurately forecast floods using satellite signals", Journal of Hydrology, vol. 572, 2019, pp. 75-79.

[13] L. Alfieri, E. Zsoter, S. Harrigan, F.A. Hipra, C. Lavaysse, C. Prudhomme, P. Salamon, "Rangedependent thresholds for global flood early 
warning”, Journal of Hydrology X, vol. 4, 2019, pp. 1-10.

[14] S. Berkhahn, L. Fuchs, I. Neuweiler, "An ensemble neural network model for real-time prediction of urban floods", Journal of Hydrology, vol. 575, 2019 , pp. 743-754.

[15] S. Park, M. Berenguer, D. Sempere-Torres, "Longterm analysis of gauge-adjusted radar rainfall accumulations at European scale", Journal of Hydrology, vol. 573, 2019, pp. 768-777.

[16] A. Bukvic, J. Harrald, "Rural versus urban perspective on coastal flooding: The insights from the U.S. Mid-Atlantic communities", Climate Risk Management, vol. 23, 2019, pp. 7-18.

[17] F. Policelli, A. Hubbard, H. Chul Jung, B. Zaitchik, C. Ichoku "A predictive model for Lake Chad total surface water area using remotely sensed and modeled hydrological and meteorological parameters and multivariate regression analysis", Journal of Hydrology, vol. 568, 2019, pp. 10711080 .

[18] T. Cowan, M.C. Wheeler, O. Alves, S. Narsey, M.K. Hawcroft, "Forecasting the extreme rainfall, low temperatures, and strong winds associated with the northern Queensland floods of February 2019", Weather and Climate Extremes, vol. 26, 2019, pp. $1-14$.

[19] X. Zhang, P. Liu, L. Cheng, Z. Liu, Y. Zhao, “A back-fitting algorithm to improve real-time flood forecasting", Journal of Hydrology, vol. 562, 2018, pp. $140-150$.

[20] E.A. Shakhray, D.L. Piotrovsky, "Prediction of floods in the Krasnodar Territory", IX International Scientific and Practical Conference of Young Scientists dedicated to the 58th anniversary of the flight of Yu.A. Gagarin into space, Krasnodar: South, 2019, pp. 559-560.

[21] D.S. Gundrov, "Automated system for monitoring and forecasting the flood situation at water bodies of the Krasnodar Territory and the prospects for its development", Problems of ensuring safety in responding to emergency situations, vol. 1, 2018, pp. 155-157.

[22] S.V. Borsch, Yu.A. Simonov, A.V. Khristoforov, "Flood forecasting system and early warning of floods on the rivers of the Black Sea coast of the Caucasus and the Kuban basin", Transactions of the Hydrometeorological Research Center of the Russian Federation, No. 356, 2015, pp. 1-247.

[23] S. Barbetta, G. Coccia, T. Moramarco, E. Todini, "Real-time flood forecasting downstream river confluences using a Bayesian approach", Journal of Hydrology, vol. 565, 2018, pp. 516-523.

\section{About the authors}

Evgeny V. Palchevsky, PhD student, Department of Geographic Information Systems, Ufa State Aviation Technical University. E-mail: teelxp@inbox.ru.

Olga I. Khristodulo, Doctor of Technical Sciences, Professor, Department of Geoinformation Systems, Ufa State Aviation Technical University. E-mail: o-hristodulo@mail.ru.
Sergey V. Pavlov, Doctor of Technical Sciences, Professor, Department of Geoinformation Systems, Ufa State Aviation Technical University. E-mail: psvgis@mail.ru. 